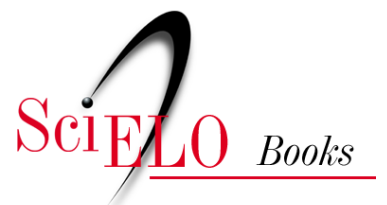

\title{
13 - A luz de Marghe (Rita), nasce uma nova esperança: memórias de uma camponesa do oeste potiguar
}

\author{
Ana Cláudia de Andrade Costa \\ Kyara Maria de Almeida Vieira
}

\section{SciELO Books / SciELO Livros / SciELO Libros}

COSTA, A. C. A., and VIEIRA, K. M. A. A luz de Marghe (Rita), nasce uma nova esperança: memórias de uma camponesa do oeste potiguar. In: OLIVEIRA, G. M. C., and VIEIRA, K. M. A., eds. Patrimônio, povos do campo e memórias: diálogos com a cultura, a arte e a educação [online]. Mossoró: EdUFERSA, 2020, pp. 193-206. ISBN: 978-65-87108-09-4. https://doi.org/10.7476/9786587108605.0014.

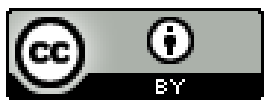

All the contents of this work, except where otherwise noted, is licensed under a Creative Commons Attribution 4.0 International license.

Todo o conteúdo deste trabalho, exceto quando houver ressalva, é publicado sob a licença Creative Commons Atribição 4.0. 


\section{A LUZ DE MARGHE (RITA), \\ NASCE UMA NOVA ESPERANÇA: \\ MEMÓRIAS DE UMA CAMPONESA \\ DO OESTE POTIGUAR}

Ana Cláudia de Andrade Costa

Kyara Maria de Almeida Vieira

Em tempos de ataques diretos às pesquisas da área da Ciências Humanas e Sociais, o capítulo que aqui apresentamos surge como um ato de resistência. Resultado de uma pesquisa ${ }^{48}$ desenvolvida em cinco (5) Projetos de Assentamento (P. A.) do Oeste Potiguar, a partir dela não apenas dados foram coletados, mas também ocorreu o encontro (de sonhos) de uma jovem moça trilhando seus caminhos acadêmicos e uma mulher que já havia trilhado uma longa e bonita caminhada de luta pelo acesso à terra. Estas linhas grafadas produzem/produziram afetos que se reatualizam. Inclusive a saudade daquela manhã de domingo, com cheiro de café quentinho, pamonha, risos frouxos e a presença forte de Dona Rita.

A História produz a possibilidade de nos dar acesso às experiências de pessoas que vivem às margens, esquecidas e/ou silenciadas pela sociedade. Mas são essas histórias que nos dão sentido e nos instigam a estudá-las porque suas vidas são menos prováveis de serem documentadas nos arquivos (THOMPSON, 1992).

\footnotetext{
48 A pesquisa foi desenvolvida a partir de projeto da Iniciação Cientifica (UFERSA) vinculado ao curso de Licenciatura Interdisciplinar em Educação do Campo, e teve parte financiada pelo CNPq. Parte dos resultados da pesquisa foi apresentada no Relatório Final da Iniciação Científica (UFERSA/ CNPq) e no Seminário de Iniciação Científica (SEMIC-UFERSA).
} 
O que acontece é que em muitas vezes temos dificuldade de considerar como acontecimentos reais o que não fora vivenciado por todas as pessoas ou por aquelas consideradas "dignas" de compor as histórias aqui publicitadas. Essa pesquisa foi desenvolvida através da história oral, a partir de entrevista semiestruturada ${ }^{49}$, e dos retalhos de memórias que bordam novas histórias. O método de história oral tem trazido grandes possibilidades para a investigação das experiências dos sujeitos históricos; a partir da memória tem-se a (re) significação das narrativas sobre si e sobre o mundo (VIEIRA, 2016).

Desta feita, o objetivo principal desse capítulo é analisar a história de vida de uma das colaboradoras da nossa pesquisa, dando destaque às memórias e à produção de saberes existentes no meio rural. Como afirma Patai (2010, p. 19) “[...] não há vidas sem sentidos, e não há histórias de vida sem significado. Existem apenas histórias de vida com as quais nós (ainda) não nos preocupamos". Nesse sentido precisamos dizer que aquilo que é significativo continua vivo, e faz parte da construção social da memória.

Dito isto, o nosso capítulo será centrado nas narrativas e nas memórias de Dona Rita, que faleceu poucos meses antes de terminarmos esse texto $^{50}$. Rita é o diminutivo do nome italiano Margherita, que deu origem à Margarida, do latim Margarita, que quer dizer literalmente "pérola". Para os gregos significa "criatura de luz" e era assim que Dona Rita, uma camponesa potiguar, se mostrava: iluminada, rara, valente. Tinha a delicadeza e a alegria de uma margarida que torna o ambiente agradável, e a força e teimosia das flores da caatinga que insistem em aflorar mesmo em tempos difíceis.

49 Os recortes da entrevista são colocados no capítulo tal qual foram ditos por nossa colaboradora em respeito à sua forma de falar. Encontra-se destacado em itálico ao longo do texto.

50 Além de toda riqueza de detalhes e da complexidade das experiências narradas por Dona Rita sobre os povos do campo, o que por si só justificaria esse texto, também aqui o escrevemos com o propósito de homenageá-la, tendo em vista que a sua trajetória de luta e o legado que deixou para quem teve o privilégio de conviver com ela, sendo ou não membros do MST. 
Nascida no dia 24/10/1945 na cidade de Mossoró-RN, casou aos 27 anos, teve 13 filhos, 13 netos e 3 bisnetos. Perdeu seu esposo e com 55 anos ficou sozinha com seus/as filhos/as, enfrentando as batalhas diárias. Um dos seus grandes sonhos era dar uma casa para sua filha, mas não tinha condições financeiras para tal. Então soube, através de uma amiga, que estavam ocupando uma terra na estrada entre Mossoró-RN e Baraúnas-RN (às margens da Rodovia RN-015). Dona Rita foi em busca de seu sonho, e ficou acampada junto aos companheiros/as, buscando um pedaço de chão:

Muler, é o seguinte: quando surgiu que ia ocupar essa terra, [...] fiquei balanciada pa vim, pá num vim. Aí quando foi um dia, chegou uma amiga minha e disse: Rita, mulher vamos! Cê vai? Eu digo: muler eu num sei se eu vou não. Achava tão difícil, porque eu não tinha transporte para vim de Mossoró prá cá, né? Aí quando foi [...] eu digo: mulher, eu vou testar, um dia vou testar, se der certo, eu fico. Aí quando foi com três dias, eu disse para ela que ia, nós viemos a pé, lá do Belo Horizonte ${ }^{51}$ (RITA, 2017).

O acampamento iniciou em 2004, e depois de muita resistência, conseguiram as casas em 2008. Finalmente Dona Rita conseguiu dar a casa para sua filha, de quem se tornou agregada ${ }^{52}$, no assentamento que ela ajudou a fundar: o Projeto de Assentamento (P.A) Nova Esperança este que em 2018 (momento da pesquisa) tinha 175 moradores/as.

51 Belo Horizonte é um dos 31 bairros localizado na cidade de Mossoró, no estado de Rio Grande do Norte. Neste bairro existem 25 ruas. Disponível em: https://applocal.com.br/bairro/belo-horizonte/mossoro/rn. Acesso em: 12 jun. 2019.

52 Agregados/as são pessoas que construíram/constroem casas nos Projetos de Assentamentos depois da efetivação dos mesmos. Quem tem esse direito são filhos ou pais e mães dos/as assentados/as. 
O P. A. Nova Esperança tem uma estreita relação com o $\mathrm{MST}^{53}$, aspecto que o diferencia dos outros quatro assentamentos pesquisados ${ }^{54}$. Dona Rita nos relatou que a dinâmica de organização do P. A. Nova Esperança se dá de acordo com as práticas do MST. No assentamento tem duas associações, como cita a mesma: "[...] É porque nós somos uma associação do MST, somos 55 famílias; só o resto é do sindicato". Dona Rita era militante do movimento e não escondia o respeito pelo MST.

Questionamos Dona Rita sobre os meios de sobrevivência do assentamento, e se o assentamento recebeu ou recebia assistência técnica. Ela nos relatou que não, que tudo de assistência que tinha de receber já receberam e o meio de sobrevivência são: "[...] Na agricultura, que todos prantam (sic), que tem como se manter né? Mas quando num tem, tem que ir pra rua, porque num vai morrer de fome".

E a mulher que fez parte de uma ocupação para conseguir dar uma casa para sua filha, não apenas passou a morar no assentamento, mas ampliou a presença de sua família:

[...] Eu vim pra minha filha, porque ela não tinha condições de possuir uma casa, e nem eu de dar uma casa a ela. Eu digo, eu vou dar uma agora [...]. Fiquei e venci, estou vencendo, aí trouxe mais três filhos e pronto.

Junto com o sonho e a luta de amparar filhas/os dando-lhes moradia, a mesma realizou outro grande sonho que foi formar três das suas filhas no primeiro curso do Rio Grande do Norte voltado para as populações do campo, o Pedagogia da Terra, realizado pela Universidade Estadual do Rio Grande do Norte, em 2006:

53 “O Movimento Sem Terra está organizado em 24 estados nas cinco regiões do país. No total, são cerca de 350 mil famílias que conquistaram a terra por meio da luta e da organização dos trabalhadores rurais. Mesmo depois de assentadas, estas famílias permanecem organizadas no MST, pois a conquista da terra é apenas o primeiro passo para a realização da Reforma Agrária". Disponível em: https://mst.org. br/quem-somos. Acesso em: 19 mar. 2020.

54 A pesquisa também foi realizada nos Projetos Assentamento Nova Vida (Upanema-RN), São Manoel e Tabuleiro Grande (Apodi-RN), Prof. Maurício de Oliveira (Assu-RN). 
Ah, foi um sonho, vixi Maria! Eu dizia a meu Deus, dizia assim: Jesus, o Senhor é maravilhoso, só assim agora, eu vou formar minhas filhas. Meu pai eterno, obrigado. Foi a maior alegria da vida. Eu me ofereci até para cozinhar (RITA, 2017).

O esmero de Dona Rita quando falava do curso demonstrava quanto valorizava a Educação. Ela narrou como o Curso de Pedagogia da Terra anunciou novos tempos para jovens, mulheres e homens do campo. Uma luta diária para conseguir resistir aos percalços encontrados. Ela nos disse que se ofereceu para fazer a comida dos/das estudantes pelo fato das filhas estudarem, mas também gostar das/dos outros estudantes de forma especial: "[...] eram meus filhos, eles me respeitavam sabe, me cativavam demais, eu tenho um amor grande por todos".

É importante frisar que o curso de Pedagogia da Terra é oriundo das lutas dos Movimentos Sociais para que as populações do campo tenham acesso à uma educação gratuita e de qualidade, rompendo com o histórico processo de exclusão educacional das populações campesinas.

A Educação do campo é uma modalidade de ensino que tem como objetivo a educação de crianças, jovens e adultos que vivem no campo. Portanto, trata-se de uma política pública que possibilita o acesso ao direito à educação de milhares de pessoas que vivem fora do meio urbano e que precisam ter esse direito garantido nas mesmas proporções em que é garantido para a população urbana (RODRIGUES; BONFIM, 2017, p. 1374).

Com o intuito de reivindicar os direitos dos povos campesinos, a educação do campo vinha sendo fortalecida nos últimos anos, e passou a ter maior visibilidade sobretudo entre os anos de 1997 e 2004, em razão de reivindicação dos diversos movimentos sociais e organizações. Assim, no período supracitado

[...] aconteceu a espacialização da Educação do Campo através de diversos movimentos e organizações. A criação de cursos novos e a difusão do referencial teórico nas escolas geraram experiências que foram desdobradas em reflexões, estudos e pesquisas. Nesse processo foram envolvidos outros movimentos camponeses, como o Movimento 
dos Pequenos Agricultores-MPA, Movimento dos Atingidos por Barragens-MAB, Movimento das Mulheres Camponesas-MMC (FERNANDES; MOLINA, 2005, p. 12).

Algumas conquistas podem ser percebidas a partir de documentos legais e de políticas públicas (Diretrizes da Educação do Campo/ PRONERA ${ }^{55}$ / PROCAMPO ${ }^{56}$ ). Dentre as conquistas asseguradas à população do campo está o direito ao acesso à escola no campo, em seu lugar de origem, com uma educação que atenda às especificidades da sua realidade. Conseguir um curso de formação de professor/a para atuar no campo, foi um grande marco para a população camponesa do Brasil e do Oeste Potiguar.

O curso de Pedagogia da Terra é um exemplo dessas conquistas, e da resistência dos movimentos sociais. Dona Rita citou que o MST foi um dos precursores na luta para a efetivação do curso na cidade de Mossoró-RN. O brilho nos olhos da mesma quando falava dos "seus meninos e meninas", como dizia ela, nos fez pensar nas mães e nos pais desses sujeitos que saiam/ saem de casa em busca de um sonho, e na importância dos Movimentos Sociais para a luta em defesa de direitos para as pessoas menos favorecidas.

Em seus relatos Dora Rita se colocava no lugar de provedora, da que definia a vida dos filhos/as. Ao mesmo tempo em que assumia papeis associados ao masculino (força, coragem, provedora e ordenadora de filhos/as), também assumia papeis de afeto, amor, cuidados do espaço doméstico e da alimentação. Como afirma Louro (2000, p.11), "A inscrição dos gêneros feminino ou masculino - nos corpos é feita, sempre, no contexto de uma determinada cultura e, portanto, com as marcas dessa cultura". Todavia,

55 PRONERA: O Programa Nacional de Educação na Reforma Agrária criado no ano de 1998 propõe e apoia projetos de educação voltados para o desenvolvimento das áreas de reforma agrária. Disponível em: http://www.incra.gov.br/educacao_pronera. Acesso em: 19 mar. 2020.

56 PROCAMPO: O Programa de Apoio à Formação Superior em Licenciatura em Educação do Campo apoia a implementação de cursos regulares de licenciatura em educação do campo nas instituições públicas de ensino superior de todo o país, voltados especificamente para a formação de educadores para a docência nos anos finais do ensino fundamental e ensino médio nas escolas rurais. Disponível em: http://portal.mec.gov.br/tv-mec. Acesso em: 19 mar. 2020. 
essas inscrições não são imutáveis ou inquestionáveis: “[...] homem e mulher não é um simples fato ou uma condição estática, e sim uma construção ideal forçosamente materializada através do tempo" (BUTLER, 2003, p.18).

Dona Rita, mesmo sendo uma das pessoas que mais lutou para permanecer na terra, que lutou em busca de melhorias para sua comunidade e que nunca permitiu que seu marido mandasse nas suas escolhas, em alguns momentos fazia discursos em relação às mulheres que nos inquietavam, quando citou, por exemplo, que "[...] A unidade das mulheres é mais ambiciosa do que os homens, né? Elas botavam os homens na perdição (RITA, 2017).

Ao afirmar "Elas botavam os homens na perdição" Dona Rita atualiza a percepção cultural de que as mulheres trazem perigo. Como afirma Ferreira (2002, p. 11):

Partindo do fato de que a bíblia é um "documento" fundador da civilização ocidental cristã, destaca-se que nela foi construída a primeira imagem da mulher, Eva. Criada a partir de uma costela de adão, ela já nasce como um ser inferior ao homem. E devido à tentação exercida sobre ele, provocou a "queda" a perda do paraíso. Daí a face negativa associada a mulher (FERREIRA, 2002, p. 11).

No relato de Dona Rita, não partia do homem a ideia de sair, de ir para a bodega ${ }^{57}$; partia das mulheres, "maliciosas e astutas". Dialogando com o autor acima citado identificamos a relação da tentação de Eva para com Adão, e a tentação das mulheres do curso para irem a bodega se divertir, insistindo e convencendo Kezim (colega de turma das estudantes do Curso de Pedagogia da Terra) a levá-las à bodega, já que só podiam sair na companhia de um homem:

Elas diziam assim, peça a Dona Rita, que ela só deixa se você for, que era um rapaz chamado Kezim, uma pessoa mermo amoroso, tudo delas era Kezim, Kezim, num sei o que, chamando ele pra conversa [...] Tinha

57 Segundo o Dicionário Online de Português (DICIO) bodega é Pequeno armazém onde se comercializam produtos de primeira necessidade, artigos diversos etc.; venda, comércio. Disponível em: https://www.dicio.com.br/bodega. Acesso em:11 fev. 2020. 
a budega lá em Dior. Elas dizia: Dona Rita? Eu digo: Que é? "Vamo saindo". "Pra onde?" "Vou ali". "Venha logo viu, tou aqui esperando. Vou cuspir no chão viu, esperando vocês (RITA, 2017).

A narrativa de Dona Rita não apenas indica que as mulheres não tinham autonomia para saírem a sós, mas, recoloca a necessidade de ter olhos que as vigiassem e as corrigissem caso fizessem algo "errado" aos olhos masculinos. Mesmo Kezim sendo amoroso, mesmo sendo uma mulher (Dona Rita) que dava a permissão para "as moças da Pedagogia da Terra" saírem para a bodega, os olhos e a presença do masculino era a "segurança" que essas mulheres teriam seus cuidados e não fariam "nada de errado".

Mas, mesmo pensando que mulheres são astutas, mesmo dando ao masculino lugar de controle dos corpos das mulheres, Dona Rita as permitia ir para a diversão (a bodega), sob os cuidados de um homem que era de sua "confiança". E essa narrativa reforça os preceitos do patriarcado e da dificuldade de conjugar ser mulher e ter liberdade em nossa sociedade.

Além de considerar a escolha de religiosa de Dona Rita (Católica) é preciso considerar sua educação, posto que era uma mulher com mais de 60 anos, que atravessou a segunda metade do século XX num Brasil conservador sob o julgo da Ditadura Civil Militar (1964-1985), esta que travou ainda mais as mudanças quanto aos direitos das mulheres sobre si próprias. Essas percepções dos papeis distintos e hierárquicos para homens e mulheres não se limitam a uma determinada classe. Como afirma Grünnagel (2015, p. 1):

Isso é em todas as classes. O que talvez mude seja o nível de desenvolvimento cultural de algumas camadas da sociedade, muito pequenas, talvez mais cosmopolitas, ou que têm uma formação educacional, cultural, mais privilegiada. Nelas isso tem diminuído. Mas é muito minoritário. É um país extremamente machista, o Brasil (GRÜNNAGEL, 2015, p. 1).

Dona Rita questiona a fixidez das identidades, posto que não foi uma mulher submissa, porque ela não se colocava enquanto sujeito que aceitava ser dominada (mesmo autorizando Kezim a vigiar as alunas do Pedagogia da Terra), que nunca permitiu que seu marido interferisse nas suas escolhas: "[...] eu dizia muito a ele: nem eu mando na sua vida e nem você manda na 
minha, pronto! E vivemos 35 anos". Sem nunca ter ido à escola, Dona Rita fez circular a dança das identidades, rompeu alguns grilhões ao assumir posições e liderar sua própria vida em muitos momentos.

Ainda nas suas múltiplas posturas, ela também não aceitava as filhas e netas usarem roupas curtas, era contra mulher ir para bares e a afirmou: "[...] Eu acho que cada pessoa deve conhecer seu lugar, né"? E ratifica: "Cada pessoa tem um jeito, eu fui criada desse jeito". Reconhecer que a "criação”, a forma como fomos educados/as nos orienta a estar no mundo, a ler o mundo, embora destaque o papel da cultura, tais falas foram usadas por Dona Rita para justificar sua opinião quanto a "cada pessoa deve conhecer seu lugar". Nesse sentido, nossa colaboradora não esteve imune aos tentáculos da nossa cultura, que ainda mantem ideal do sujeito unívoco e centrado (HALL, 2005); cultura a partir da qual aos homens é reservado a liberdade, os espaços públicos e as diversões a partir do exercício de sua sexualidade, e às mulheres é reservado a contenção, os espaços privados, cuidados com a casa e a família, a castidade/ virgindade e fidelidade aos seus esposos.

Acontece que as identidades apresentam mudanças, estas que ocorrem de acordo com as experiências vivenciadas, e por isso as percepções de Dona Rita também vivenciam mudanças. Mesmo estabelecendo regras para os corpos de suas filhas e netas, estas já assumiam posturas diferentes das de Dona Rita. Segundo Hall (2005, p. 7), “(...) as velhas identidades, que por tanto tempo estabilizaram o mundo social, estão em declínio, fazendo surgir novas identidades e fragmentando o indivíduo moderno, visto como um sujeito unificado".

A doce e afetuosa, brava, séria Rita seguiu contando sua experiência no assentamento que ajudou a construir, dizia dos dias de muita luta, que comandava moradores junto com mais dois colegas. Ela era uma grande referência na comunidade. Em seu relato, afirmou:

Logo eu trato eles bem, eu respeito eles, eu converso com eles, eles vêm aqui, muitas das vezes: "Dona Rita, vim aqui pra senhora me dar isso assim, assim, resolver isso por mim. Eu posso fazer?" Eu digo assim: Senta aí, vamos conversar, vamos ver, se num der certo você vai simbora (sic), se der, você vai fazer (RITA, 2017). 
Partindo dessa visão percebemos que Dona Rita se colocava como mãe, protetora, que indicava o caminho certo, uma espécie de conselheira que definia a vida dos/as filhos/ e daqueles/as que a buscavam. Os moradores do P.A Nova Esperança e os/as estudantes do Curso de Pedagogia da Terra construíram laços afetivos e realizaram sonhos junto com Dona Rita. Como bem diz Ricoeur (1965/1977 apud MEDEIROS, 2015, p. 17-18):

[...] esse termo - sonho — não é um termo que fecha, mas que abre. Não se fecha sobre um fenômeno até certo ponto marginal de nossa vida psicológica, sobre a fantasia de nossas noites, sobre o onírico. Ele se abre a todas as produções psíquicas enquanto são análogas ao sonho, na loucura e na cultura, quaisquer que sejam seu grau e o princípio desse parentesco.

Esse sonho foi idealizado por muitos durante muito tempo, e foi realizado depois de muitos sacrifícios. Como diz Ricoeur (1965/1977), sonhos que abriram clareiras para trilharem novos caminhos e Dona Rita sentia-se orgulhosa de ter feito parte desse processo: “[...] A faculdade foi um exemplo, pra nós e pra quem estudou, porque foi dentro da faculdade que eu aprendi amar as pessoas". A narrativa de Dona Rita nos faz pensar na importância das relações, mas também na importância de acessar uma educação gratuita e de qualidade. O que era um sonho de Dona Rita estava relacionado com a possibilidade de mudança de vida para suas filhas e pessoas que conheceu durante o curso Pedagogia da Terra e, nesse sentido, a Educação do Campo rompeu com a visão do campo apenas como fator produtivo, apresentando-nos o campo como espaço de vida e resistência, onde camponeses/as lutam por acesso e permanência na terra, com vistas a fortalecer e garantir um modo de viver que respeite as diferenças quanto à relação com a natureza, com o trabalho, com a cultura, com as pessoas (FERNANDES; MOLINA, 2005, p. 09).

Ao concluirmos esse texto, destacamos a importância das memórias, que nos trouxeram sentimentos distintos, ora de saudade, ora de alegria por termo tido a oportunidade de dialogar com Dona Rita e tê-la como uma colaboradora da nossa pesquisa. 
Nos depararmos com as reminiscências estimuladas pela (re) escrita de um trabalho nos permite pensar que não somos mais os/as mesmos/as, percebemos que a vida, os sentimentos, os fatos não permanecem iguais. Tudo muda, ganha um novo significado dentro daquilo que foi/é singular em um dado momento. Mas, acima de tudo, a pesquisa ratifica que "É preciso conhecer, reconhecer, [...] respeitar e afirmar a diversidade sociocultural dos povos que vivem/habitam no campo e do campo" (QUEIROZ, 2011, p. 43).

Para além das memórias afetuosas, do sorriso, da voz doce e do café quentinho de Dona Rita, podemos conhecer outras realidades, descobrir outros lugares e ter contato com histórias de pessoas que continuam a existir e resistir no semiárido rural nordestino. Ao centrar-se nas narrativas de Dona Rita, esse texto reverbera as memórias de uma camponesa forte, meiga e valente que, mesmo diante dos desafios de ser mulher na nossa sociedade, deixou um legado de lutas, vitórias e inspiração para gerações vindouras, já que sua trajetória borra a percepção tão naturalizada ainda de que o rural se trata apenas de do produtivismo, onde o campo só é visto como lugar de produção de mercadorias e não como espaço de vida (FERNANDES; MOLINA, 2005).

Por fim, a partir da experiência de Dona Rita, destacamos que suas histórias nos trouxeram a complexidade da vida com uma mistura de poesia e crueza, nos mais variados espaços. Percebemos que é possível atravessar diferentes temporalidades, nos possibilitando compreender a multiplicidade do que podemos ser enquanto sujeitos de nossa própria história. Esperamos então que nosso texto permita, a partir da luz de Marghe (Rita), nascer uma nova esperança. 



\section{REFERÊNCIAS}

BUTLER, J. Problemas de gênero. Rio de Janeiro: Civilização Brasileira, 2003.

FERNANDES, B. M.; MOLINA, M. C. O Campo da educação do campo. [S.l.:s.n.]2005. Disponível em: https://bit.ly/2FtohNJ. Acesso em: 16 jul. 2019.

FERREIRA, C. A. A Mulher na literatura portuguesa: sua imagem e seus questionamentos através do gênero epistolar. São Paulo: FFLCH, 2002. p. 48-60.

GRÜNNAGEL, C. No Brasil, mesmo as mulheres são machistas: [entrevista com] Bernardo Ajzenberg. Estudos de Literatura Brasileira Contemporânea, n. 45, 2015. Disponível em: https://bit. ly/2H1nW5p. Acesso em: 29 maio 2019.

HALL, S. A Identidade cultural na pós-modernidade. Tradução de Tomaz Tadeu da Silva e Guacira Lopes Louro. 11. ed. Rio de Janeiro: DP\&A, 2005.

LARROSA, J. Notas sobre a experiência e o saber de experiência.

Revista Brasileira de Educação, n. 19, jan./abr. 2002. Tradução João Wanderley Geraldi. Disponível em: https://www.scielo.br/pdf/rbedu/ n19/n19a02.pdf. Acesso em: 14 set. 2020.

LOURO, G. L. 0 Corpo educado: pedagogias da sexualidade. Belo Horizonte: Autêntica, 2000. 
MEDEIROS, J. T. Paul Ricoeur, leitor de Freud: contribuições da psicanálise ao campo da filosofia hermenêutica. Natureza humana, v. 17, n. 1, 2015. Disponível em: https://bit.ly/33yU7AS. Acesso em: 14 set. 2019.

PATAI, D. História oral, feminismo e política. São Paulo: Letra e Voz, 2010.

QUEIROZ, J. B. P. A Educação do campo no Brasil e a construção das escolas do campo. Revista Nera, v. 14, n. 18, p. 37-46, jun. 2011.

RICOEUR, P. Tempo e narrativa: tomo I. Campinas: Papiros, 1994.

RODRIGUES, H. C. C.; BONFIM, H. C. C. A Educação do campo e seus aspectos legais. In: SEMINÁRIO INTERNACIONAL DE REPRESENTAÇÕES SOCIAIS, SUBJETIVIDADE E EDUCAÇÃO, 4., 2017, Curitiba. Anais [...]. Curitiba: Sirsse, 2017. p. 1-15.

THOMPSON, P. A Voz do passado-história oral. Rio de Janeiro: Paz e Terra, 1992.

VIEIRA, K. M. A. A Única coisa que nos une é o desejo: produção de si e sujeitos do desejo na vivência do homossexualismo em Campina Grande-PB. 2016. Dissertação (Mestrado em Ciências Sociais) Universidade Federal de Campina Grande, Campina Grande, 2006.

VIEIRA, K. M. A. História e memória: comunidades rurais do semiárido nordestino e suas práticas culturais. Mossoró: UFERSA, 2016. Projeto de Pesquisa PIBIC. 